\title{
Thermoguided Lipolysis and Skin Tightening Technique with 980nm Diode Laser
}

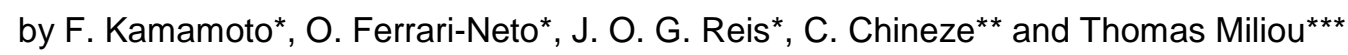 \\ * Hospital da Plástica, Plastic Surgery Department, 905, Bom Pastor Str, 04203-050 São Paulo, SP, \\ fabio.kamamoto@gmail.com, orlandoferrari@gmail.com, jureis@gmail.com \\ **Kamamoto Clinic, 306, Mato Grosso Str., 01239-040, São Paulo, SP, Brasil, carla@clinicakamamoto.com.br \\ ***oliscan Medical Technologies, 180, Guapuruvu Str., 13098-324 São Paulo, SP, Brasil \\ diretoria@poliscanbrasil.com.br
}

\begin{abstract}
INTRODUCTION: Liposuction is a well-established procedure to improve body contour through the use of laser in order to reach lipolysis and skin retraction. The current parameters in the devices allow an indirect inference of skin temperature changes. This article presents the authors' experience with laser lipolysis, though an Infrared Camera guidance, providing a secure measurement method for optimal results of the procedure and its effect on tissues.

METHODS: This study included 83 female patients who underwent laser lipolysis.

RESULTS: No skin burn wounds were registered.

CONCLUSIONS: Laser lipolysis performed according to the described technique was safe and reproducible.
\end{abstract}

\section{Introduction}

The liposuction is nowadays a standard procedure in the plastic surgery for the treatment of body contour irregularities and the second most common plastic surgery aesthetics in Brazil [1]. The lipodistrofia treatment was described for the first time in the 1983 publication by for the French surgeon Illouz [2] and has undergone several technical improvement evolutions.

The treatment consists of the removal of the subcutaneous tissue of the affected areas with the preservation of the skin. After the removal by vacuum of the fat excess, it is assumed that the skin's natural capacity for retraction (elasticity), it will adapt to the reduction of volume of the subcutaneous tissue.

However this skin adaptation does not always occur, especially in areas with less thickness of the skin as the medial face of the thighs and the arms. That can implicate in a non desirable side effect such as skin flabbiness, and to require the retreat of the skin in excess, creating a scar.

Different laser types exist that can be applied in the subcutaneous tissue with the objective to provoke lipolysis and skin retraction[3]. Lasers with wavelength of $980 \mathrm{~nm}$ present great affinity due to the water contained in the adipocytes and the skin. Therefore it is effective for lipolysis $[4,5]$ and as skin retraction stimulator.

The surgeon's main concern in using this technology consists in creating an excessive heat production provoking burns of the tissue. The existing parameters of the laser devices at the present moment (potency and energy) allow only indirectly to interfere at the change of temperature in the skin. Therefore the surgeon must choose between applying a laser application with a sub-dose to the tissue, without obtaining the expected results, or to provoke an undesirable burn. The surgeon lacks the necessary instruments for measuring temperature and adjusting the dose of the application.

Infrared cameras measure the infrared light and provide a tool for measuring temperatures in an indirect manner, registering radiometric images or films for a variety of current application for military purposes, industry, construction, safety, etc. The first article with a medical application was published in 1957[6] and today there are many known applications both in human and animal health, such as fever detection[7], pain management[8] or quantification of the brown adipose tissue activation[9]. It can be used to monitor inflammatory reactions in rheumatology[10], prevention of lesions in sports medicine[11] and for detection of skin tumours as melanomas and even melanoma metastasis. $[12,13]$.

In plastic surgery it can be used in the preoperative planning, detecting perforators in skin flaps, and pos operative monitoring, as a complement in the analysis of the depth of burns or in evaluation of hemangioma treatment. [14] However to the knowledge of the writers there are no published articles describing Infrared technology as a guide for the liposuction procedure with laser. 


\section{Objectives}

The objective of this research is to describe a new standardized technique of dynamic thermography which measures the temperature of the epidermis during a Laser application and consequently to guide the surgeon during the procedure to increase the efficiency and reduce the risk of health complications.

A second objective is to determine a safe limit of the temperature in order to avoid burn wound during the application of the laser.

\section{Methods}

Eighty three female patients with ages varied from 17 to 75 years old, were submitted to Laser Lipolysis with the diode laser Orlight ${ }^{\circledR}$ Duet 980nm (figure 1) in the period of June to November 2019.

For temperature monitoring a thermal camera Flir ${ }^{\circledR}$ T540sc (Flir Systems Inc, Wilsonville, OR) with IR resolution $464 \times 248$ pixels and thermal sensibility of $30 \mathrm{mk}$ and a lens of $42^{\circ}$ was used and fastened on the surgical focus to allow its manipulation from the surgeon in a sterile way (figure 2). The images of the camera were transmitted by Bluetooth to an Ipad tablet Pró 12.9 fastened in a front position to the surgeon (figure 2). A sound and visual alarm was set up in IR camera when the laser pointer temperature inside the skin reached $38^{\circ} \mathrm{C}$ (figure 3 ).

The room temperature and humidity (less than 60\%) were registered with a thermo-hygrometer HTC-1 and patients were not exposed in drafts. The medium temperature was $22^{\circ} \mathrm{C}$.

During the laser application, Lipolysis was achieved by laser application to the deep subcutaneous layer and skin tightening in the deep dermis at a speed of 5 centimetres per second. The laser pointer generates heat and can be observed with the formation of a red dot in the demarcated area (figure 4), which was simultaneously monitored by the Infrared camera. The laser was applied in the tissue until a homogeneous surface of temperature was obtained (figure 5).

To determine the temperature that provokes burn wounds in the skin, laser was applied in the deep dermis in flats of patients' abdomen that would be submitted to dermolipectomy. The temperature was monitored by the Infrared camera. The burn of the skin was defined as the appearance of an opaque plate in the surface of the skin, where a decrease of perfusion was observed.

\section{Results}

The average temperature that provoked burn wounds was of $45^{\circ} \mathrm{C}$. A safety interval between $36^{\circ} \mathrm{C}$ and $40^{\circ} \mathrm{C}$ was adopted as goal for the application. Therefore a visual and sound alarm of $38^{\circ} \mathrm{C}$ was setup in the Infrared camera.

In the medial face of the arm and thigh a power of $15 \mathrm{w}$ was used and an average of $4000 \mathrm{~J}$ of energy per region was applied. In the dorsal region and abdomen was adopted power of $20 \mathrm{w}$ and were applied $6000 \mathrm{~J}$ in each quadrant. Under the chin area was used $10 \mathrm{w}$ and applied $1500 \mathrm{~J}$. On average the initial temperature of the tissue studied was $31.2^{\circ} \mathrm{C}$, the final after laser application was $37^{\circ} \mathrm{C}$

None of the 83 participants suffered skin burn wounds during the surgery.

The use of the Infrared camera allowed a more homogeneous distribution of the laser and provided the surgeon with effective monitoring, so that an appropriate dose of energy would be applied to the subcutaneous and deep dermis, obtaining the desired effect.

\section{Discussion}

Skin tightening involves both dermal and hypodermal collagen remodelling. The generation of heat in the area of the deep dermis promotes the production of collagen, the activation of the cicatrization process, contraction of the collagen and enables a qualitative assessment of collagen fibers [15]. For that effect to happen in an appropriate way it is necessary that the heat provokes the intra and intermolecular rupture of the collagen fibres, within a certain temperature range [16].

Different technologies do apply the principal of temperature increase to induce this biological effect such as: radiofrequency, ultrasound and the laser [17]. However the excess of heat can provoke burns. According to Lawrence and Bull an object in contact with the skin for any duration of time should not exceed $42^{\circ} \mathrm{C}$ of temperature and in temperatures above $43,5^{\circ} \mathrm{C}$ tissue damage was observed [18]. Therefore it is essential a monitoring of the temperature in the epidermis to maintain a safe range of temperature while at the same time, the heat induces the demodulation of the dermis.

Several diagnostic methods such as clinical and histopathological evaluation have been employed for assessment of burn wound depth, including employing IR imaging - static thermography and active dynamic thermography (ADT). In the case of ADT registration of thermal images was performed following thermal pulse excitation. A series of captured infrared images was used as the basis for calculating the thermal time constant $\mathrm{T}$ for each pixel. The depth of the burn wound of the skin can be evaluated quantitatively calculating the thermal time constant $\mathrm{T}$. [19, 20]. The thermal images demonstrate in superficial skin burns an increase of the temperature compared with the nearby healthy area, while deep burns present lower temperatures in comparison with the nearby healthy areas. This temperature difference is statistically significant and it provides a way of distinguishing superficial to deep burns wounds.[21]. There is 
an important potential to calculate the risk of deep burn wound with the use of Infrared cameras. Although the presented technique of the dynamic thermography's objective is not an evaluation of an existent wound, nor to measure the recovery of a burn wound, such data could be of great use in a future application. In near future a software of artificial intelligence could improve the thermal monitoring of the laser lipolysis procedure providing higher efficacy and more safety.

\section{Conclusion}

The present study was designed to determine the effect of laser lipolysis with the assessment of an Infrared camera as a method that can avoid common deep burn wound in this type of procedure. The use of an Infrared camera to transmits on real time a thermal image on a monitor for manual guidance, proved statistically to offer a distinctive positive result as to burn wound and aesthetic final outcome. The authors have concluded that the proposed method offers a significant option to the plastic surgeon with higher guaranties of avoiding health complication during and after the surgery. The main objective was to avoid internal deep burn wounds that are difficult to treat and offer a preventive and proactive technique of thermo-guidance of laser lipolysis. A further study could assess the long-term effects of the proposed method.

\section{REFERENCES}

[1] http://www2.cirurgiaplastica.org.br/wpcontent/uploads/2017/12/CENSO-2017.pdf

[2] Illouz YG. "Body contouring by lipolisis: a 5- year experience with over 3000 cases", Plast Recons Surg. 1983;72(5):591-7.

[3] Weiss RA, Beasley K. "Laser assisted liposuction using a novel blend of lipid and water-selective wavelenghts." Lasers Surg Med. 2009;41 (10):760-6.

[4] Centurion P, Cuba JL, Noriega A. "Body Contouring using Laser diode 980-nm assisted Lipolysis: A Safe Procedure.”. Cir Plást Ibero-Latinoam. 2011; 37(4):355-64.

[5] Dornelles RF, Missel AL, Centurion P. "Laser lipolysis with a 980-nm diode laser: experience with 400 cases. " Rev Bras Cir Plast. 2013: 28 (1):124-9.

[6] R. Lawson, "Implications Of Surface Temperatures In The Diagnosis Of Breast Cancer”, Canad. M. A. J.,Aug. 15, 1956, vol. 75 .

[7] LS Chan et al. "Utility of infrared thermography for screening febrile subjects", Hong Kong Med J 2013;19:10915.

[8] F. S. Nahm, "Infrared Thermography in Pain Medicine", Korean J Pain 2013 July; Vol. 26, No. 3: $219-222$.

[9] Ang QY, Goh HJ, Cao Y, Li Y, Chan SP, et al. "A new method of infrared thermography for quantification of brown adipose tissue activation in healthy adults: a randomized trial." J Physiol Sci, 2017, 67: 395-406.

[10] Engel, J.-M. and Saier, U. "Thermographische Standarduntersuchungen in der Rheumatologie und Richtlinien zu deren Befundung". Luitpold, München, 1984

[11] Moreira, D. G., Costello, J. T., Brito, C. J., Adamczyk, J. G., Ammer, K., Bach, A. J., Sillero Quintana, M. "Thermographic imaging in sports and exercise medicine: a Delphi study and consensus statement on the measurement of human skin temperature." J Thermal Biol, 2017, 69, 155-162.

[12] C. Herman, The role of dynamic infrared imaging in melanoma diagnosis, Expert Rev Dermatol. 2013 April 1; 8(2): 177-184

[13] A. L. Shada, L. T. Dengel, G. R. Petroni, M. E. Smolkin, S. Acton, C. L. Slingluff Jr, "Infrared Thermography of cutaneous melanoma metastases, Surg Res. 2013 June 1; 182(1): e9-e14.

[14] H. E. John, V. Niumsawatt, W. M. Rozen, I. S. Whitaker, "Clinical applications of dynamic infrared thermography in plastic surgery: a systematic review,Gland Surg 2016;5(2):12-32.

[15] Key DJ. "Integration of thermal imaging with surface radiofrequency thermistor heating". J Drugs Dermatol 2014 Dec; 13(12): 1485-9.

[16] Sadick N. "Tissue Tightening Technologies". Aesthet Surg J. 2008; 28(2):180-8.

[17] Pritzker RN, Hamilton HK, Dover JS. "Comparison of different technologies for noninvasive skin tightening". J Cosmet Dermatol 2014;13:315-23.

[18] J. C. Lawrence, J. P. Bull, "Thermal conditions which cause skin burns”, QIMechE, 1976. Vol. 5, No.3.

[19] Renkielska A, Nowakowski A, Kaczmarek M, Ruminski J. "Burn depths evaluation based on active dynamic IR thermal imaging-A preliminary study. Burns". 2006; 32(7):867-875.

[20] Renkielska A1, Kaczmarek M, Nowakowski A, Grudziński J, Czapiewski P, Krajewski A, Grobelny I. "Active dynamic infrared thermal imaging in burn depth evaluation". J Burn Care Res. 2014 Sep-Oct;35(5):e294-303.

[21] J. D. Medina-Preciado, E. S. Kolosovas-Machuca, E. Velez-Gomez, A. Miranda-Altamirano, F. J. González, "Noninvasive determination of burn depth in children by digital infrared thermal imaging" Journal of Biomedical Optics. 2013, 18(6), 061204. 


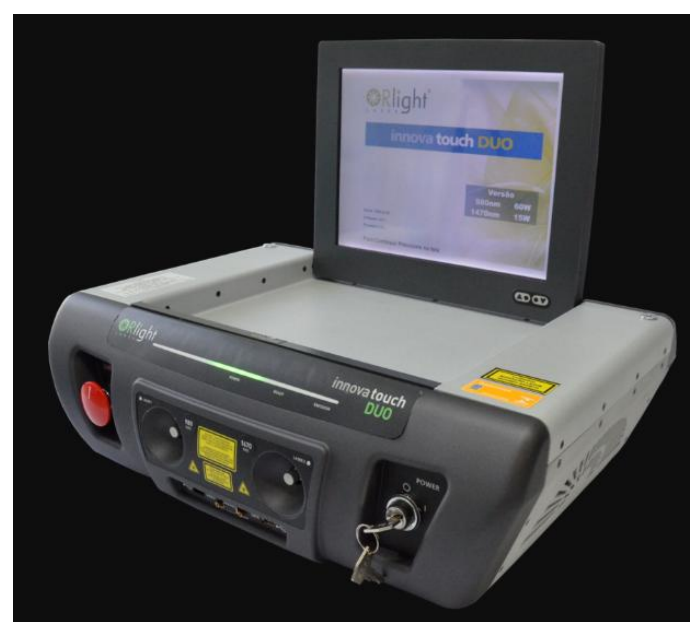

Fig. 1. Diode laser Orlight@ Duet 980nm

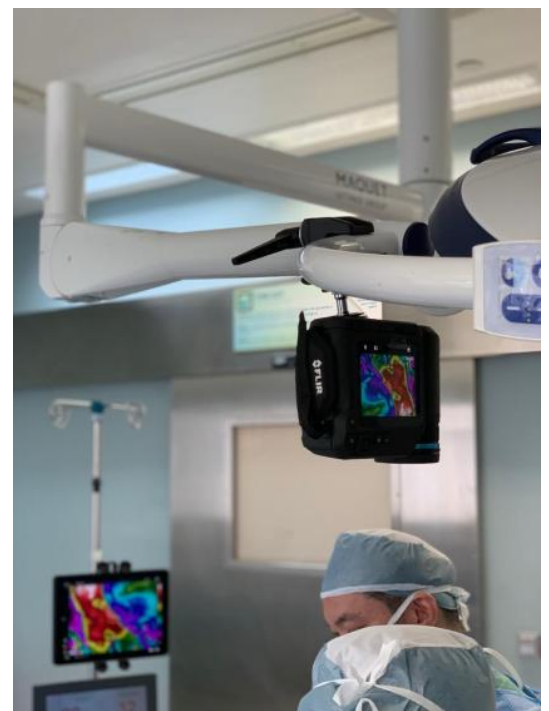

Fig. 2. IR Camera fastened on the surgical focus and simultaneous transmission to an Ipad table via Bluetooth in frontal position to the surgeon

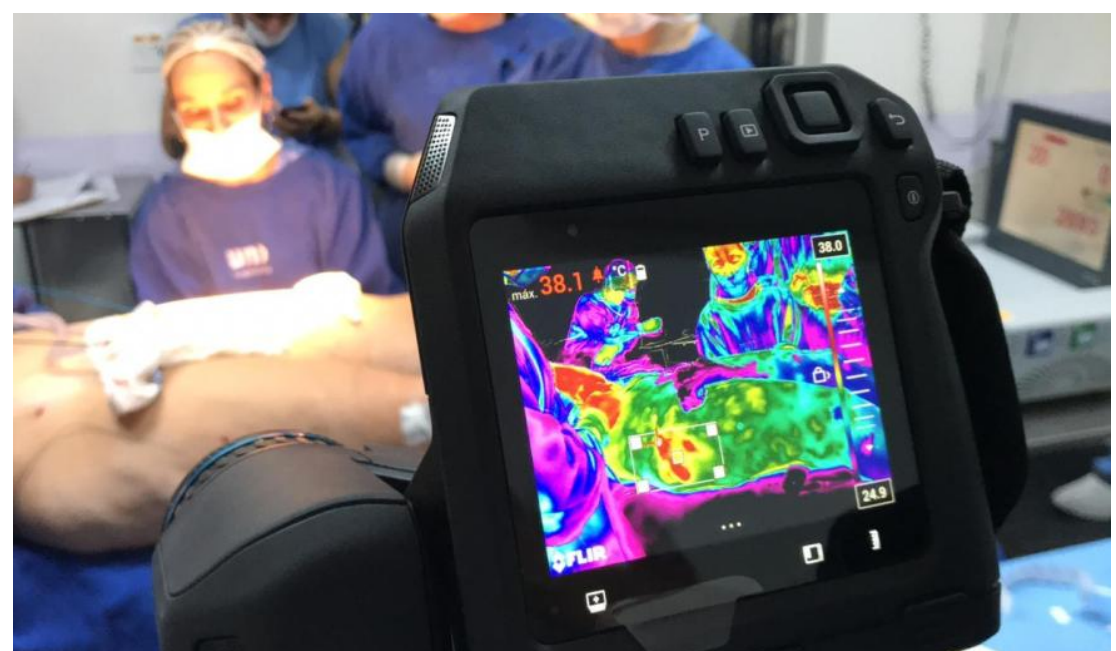

Fig. 3. A sound and visual alarm was set up in IR camera when the laser pointer temperature inside the skin reached $38^{\circ}$ 


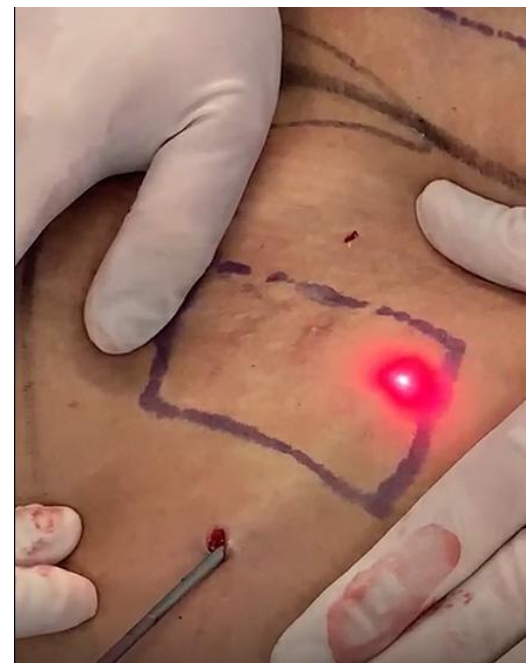

Fig. 4. The laser pointer generates heat and a red dot appears guiding the surgeon to apply the laser in the demarcated area of the skin.

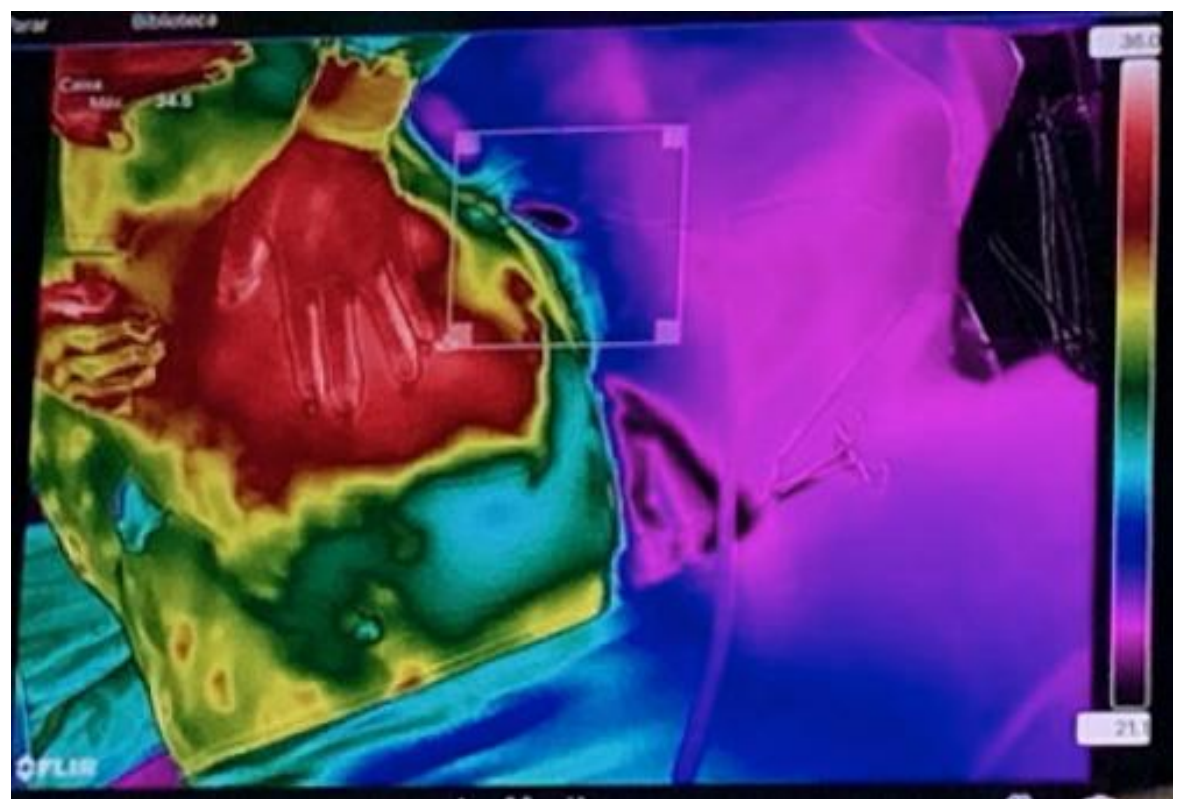

Fig. 5. When a homogeneous surface of temperature was obtained in the demarcated area, surgeon stops the laser application. 